determined, the addition of atropine to the propranololtreated heart only minimally changed the sinus cycle length (640 to $610 \mathrm{~ms}$ ). This is consistent with some decrease in vagal effect on the sinus node.

An alternative hypothesis is that effective sympathetic tone at the sinoatrial node is increased. It is possible that the atrial injury produced by radiofrequency energy can cause the same increase in $\beta$-adrenergic receptor density that is seen in myocardial ischemia. ${ }^{11}$ Furthermore, it is possible that the atrial injury produced by the radiofrequency modification procedure induces the local release of adrenergic neurotransmitters without producing systemically detectable levels. However, it seems unlikely that limited atrial injury would produce a sustained increase in $\beta$-adrenergic receptor density or sustained local release of neurotransmitters.

Another potential explanation for inappropriate sinus tachycardia in these patients is that they had preexisting paroxysmal sinus tachycardia unrelated to radiofrequency ablation, which was revealed by discontinuation of antiarrhythmic medications. However, this seems unlikely because: (1) no history of paroxysmal sinus tachycardia was noted before the initiation of drug therapy, and (2) paroxysmal sinus tachycardia is a rare disease and its coexistence with AVJRT seems even more improbable.

In this report, the only technique used for AV junctional modification was the anterior or fast pathway approach. It is not known if inappropriate sinus tachycardia may also develop when the posterior or slow pathway approach is used, nor is it known if improvements to the procedure will affect the development of this potential complication.

Thus, 3 of 8 patients who developed symptomatic, inappropriate sinus tachycardia after radiofrequency current catheter modification of the AV node were presented. This is the first report of this complication. The symptoms ranged from mild to debilitating palpitations and often needed treatment with $\beta$ blockers that are effective in controlling symptoms. It appears that in most paticnts the inappropriate sinus tachycardia may resolve over a prolonged time period, but may remain as a significant long-term problem needing treatment. It appears as if autonomic dysfunction may have an important role in the etiology of this complication; however, the role of other, unexplained factors cannot be excluded. Continued follow-up will be needed to establish the natural history of this complication, and further work is needed to elucidate its cause.

1. Josephson ME, Kastor JA. Supraventricular tachycardia: Mechanisms and management. Ann Intern Med 1977;87:346-358.

2. Borggrefe M, Budde T, Martinez-Rubio A, Hindricks G, Haverkamp W, Gulker $\mathbf{H}$. Radiofrequency catheter ablation for drug-refractory supraventricular tachycardia (abstr). Circulation 1988;78(suppl II):II-305.

3. Lee MA, Morady F, Kadish A, Schamp DJ, Chin MC, Scheinman MM, Griffin JC, Lesh MD, Pederson D, Goldberger J, Calkins H, deBuitleir M, Kou WH, Rosenheck S, Sousa J, Langberg JJ. Catheter modification of the atrioventricular junction with radiofrequency energy for control of atrioventricular nodal reentrant tachycardia. Circulation 1991;83:827 835 .

4. Calkins H, Sousa J, El-Atassi R, Rosenheck S, deBuitleir M, Kou WH, Kadish AH, Langberg JJ, Morady F. Diagnosis and cure of the Wolff-Parkinson-White syndrome or paruxysmal supraventricular tachycardias during a single electrophysiologic test. N Engl J Med 1991;324:1612-1618.

5. Leitch J, Klein G, Yee R, Murdock C. Invasive electrophysiologic evaluation of patients with supraventricular tachycardia. Cardiol Clin 1990;8:465-477.

6. Jose AD, Taylor RR. Autonomic blockade by propranolol and atropine to study intrinsic myocardial function in man. $J$ Clin Invest 1969;48:219-231.

7. Randall WC, Ardell JL. Nervous control of the heart: anatomy and pathophysiology. In: Zipes DP, Jalife J, eds. Cardiac Electrophysiology: From Cell to Bedside. Philadelphia: W.B. Saunders, 1990:291-299.

8. Forsgen $S$. The distribution of sympathetic nerve fibres in the AV node and AV bundle of the bovine heart. Histochem $J$ 1986;18:625-638.

9. Imaizumi S, Mazgalev T, Dreifus LS, Michelson EL, Miyagawa A, Bharati S, Lev M. Morphological and electrophysiological correlates of atrioventricular nodal response to increased vagal activity. Circulation 1990;82:951-964.

10. Motomura S, Iijima T, Taira N. Cholinergic intervention in intracardiac autonomic nerves in atrioventricular junctional area. Am $J$ Physiol 1980;239 (Heart Circ Physiol 8):H181-H188.

11. Susanni EE, Manders T, Knight TR, Vatner DE, Homcry CJ. One hour of myocardial ischemia decreases the activity of the stimulatory guanine nucleotide regulatory protein Gs. Circ Res 1989;65:1145-1150.

\title{
Determinants of Impedance During Radiofrequency Catheter Ablation in Humans
}

Mark Borganelli, MD, Rafel El-Atassi, MD, Angel Leon, MD, Steven J. Kalbfleisch, MD, Hugh Calkins, MD, Fred Morady, MD, and Jonathan J. Langberg, MD

$\mathbf{R}$ adiofrequency catheter ablation has become the treatment of choice for selected patients with paroxysmal supraventricular tachycardia due to atrioventricular node reentry or the Wolff-Parkinson-White syndrome. ${ }^{1-3}$ Despite encouraging results described in several series, the optimal energy delivery strategy has not been defined. Lesion formation occurs during radiofrequency ablation as the result of resistive heating at the electrode-tissue interface. ${ }^{4}$ The magnitude of heat generation is proportional to power density at the point of contact. ${ }^{5}$ Electrosurgical units currently being used for

From the Department of Internal Medicine, Division of Cardiology, University of Michigan Medical Center, 1500 E. Medical Center Drive, B1 F245, Ann Arbor, Michigan 48109-0022. Manuscript received September 30, 1991; revised manuscript received and accepted December 13,1991 . radiofrequency ablation have a low source impedance and therefore approximate constant voltage sources. With such a device, one preselects a given output voltage. Applied power is proportional to the square of this output voltage and is inversely proportional to the load impedance imposed by the ablation catheter, patient and indifferent electrode. Thus, the effectiveness of any given energy application may be influenced by the impedance of the system. This study characterizes impedance during radiofrequency catheter ablation in humans, and defines the relation between clinical and ablation parameters, and measured impedance.

Twenty-seven patients (15 men [55\%], mean age 42 \pm 19 years) undergoing radiofrequency catheter ablation in July and August 1991 were included in this study. The procedure was performed using a protocol approved 


\begin{tabular}{|c|c|c|c|c|}
\hline Patient & $\begin{array}{l}\text { Age }(y r) \\
\& \text { Sex }\end{array}$ & $\begin{array}{l}\text { Heart } \\
\text { Disease }\end{array}$ & Diagnosis & Ablation Site \\
\hline 1 & $15 \mathrm{~F}$ & 0 & WPW & Right posteroseptal \\
\hline 2 & $17 \mathrm{~F}$ & 0 & WPW & Right anteroseptal \\
\hline 3 & $17 \mathrm{M}$ & 0 & WPW & Left posterolateral \\
\hline 4 & $18 \mathrm{M}$ & 0 & WPW & Right posteroseptal \\
\hline 5 & $19 M$ & 0 & WPW & Left lateral \\
\hline 6 & $19 \mathrm{~F}$ & 0 & WPW & Mid-septal \\
\hline 7 & $26 \mathrm{~F}$ & 0 & WPW & Right posteroseptal \\
\hline 8 & $30 \mathrm{~F}$ & 0 & WPW & Right posteroseptal \\
\hline 9 & $32 \mathrm{M}$ & 0 & WPW & Right anteroseptal \\
\hline 10 & $33 \mathrm{~F}$ & 0 & WPW & Left lateral \\
\hline 11 & $38 \mathrm{M}$ & 0 & WPW & Left posterolateral \\
\hline 12 & $38 \mathrm{M}$ & 0 & WPW & Left lateral \\
\hline 13 & $41 \mathrm{M}$ & 0 & WPW & Right anterolateral \\
\hline 14 & $41 \mathrm{~F}$ & 0 & WPW & Right anteroseptal \\
\hline 15 & $46 \mathrm{M}$ & 0 & AVNRT & Fast pathway \\
\hline 16 & $47 \mathrm{~F}$ & 0 & AVNRT & Slow pathway \\
\hline 17 & $48 \mathrm{M}$ & 0 & AVNRT & Slow pathway \\
\hline 18 & $49 M$ & 0 & WPW & Left anterior \\
\hline 19 & $55 \mathrm{M}$ & 0 & WPW & Left posteroseptal \\
\hline 20 & $56 \mathrm{~F}$ & 0 & WPW & Right anteroseptal \\
\hline 21 & $65 \mathrm{~F}$ & 0 & WPW & Rlght anteroseptal \\
\hline 22 & $66 \mathrm{~F}$ & 0 & AVN ablation & His bundle \\
\hline 23 & $70 \mathrm{M}$ & 0 & WPW & Left lateral \\
\hline 24 & $52 M$ & CAD & AVN ablation & His bundle \\
\hline 25 & $59 M$ & CAD:CABG & AVN ablation & His bundle \\
\hline 26 & $67 \mathrm{~F}$ & CAD & AVNRT & Fast pathway \\
\hline 27 & $72 M$ & CAD:CABG & VT & Left ventricle \\
\hline \multicolumn{5}{|c|}{$\begin{array}{l}A \mathrm{AVN}=\text { atrioventricular node; } \mathrm{AVNRT}=\text { atrioventricular nodal reentrant tachycardia } \\
\mathrm{CABG}=\text { coronarrartery bypass graft; } \mathrm{CAD}=\text { coronary artery disease; } \mathrm{VT}=\text { = ventricula } \\
\text { tachycardia; WPW }- \text { Wolff-Parkinson-White syndrome. }\end{array}$} \\
\hline
\end{tabular}

by the human research committee of the University of Michigan Medical Center, and all patients gave informed written consent. Clinical characteristics of this cohort are listed in Table I. Structural heart disease was present in 4 patients. Catheter ablation of an accessory atrioventricular connection was performed in $19 \mathrm{pa}$ tients, ablation of the atrioventricular junction in 3, and atrioventricular nodal modification for treatment of typical atrioventricular node reentry tachycardia in 4. Pa-

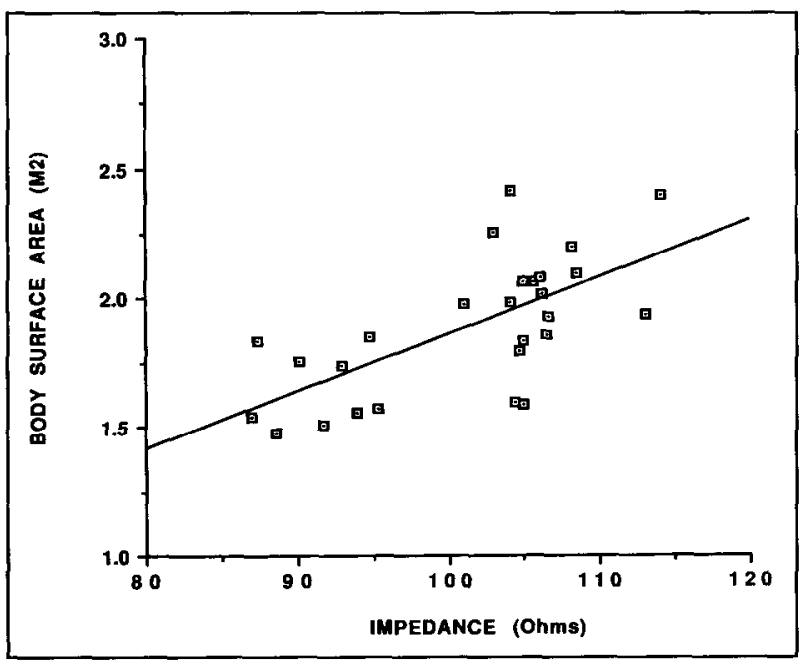

FICURE 1. Rolation between body surface area and impodance in 27 patients undergolng radifrequency catheter ablation. tient 21 had an attempt at ablation of microreentrant ventricular tachycardia in the inferobasilar aspect of the left ventricle.

The power source used in this study supplied a continuous, unmodulated output at $500 \mathrm{KHz}$ (EP Technologies, Inc., Mountain View, California). This device, through an interface with a microcomputer (T-1600, Toshiba Electronics, Japan), measures, displays and stores root-mean-square voltage, current, power and impedance during each energy application. To prevent continued current flow after coagulum formation, the device automatically discontinues power delivery if impedance is $>300$ ohms.

Electrode catheters from 2 manufacturers (Mansfield Scientific, Watertown, Massachusetts, and EP Technologies) were used for ablation. Both catheters had deflectable shafts that were $7 F r$ in diameter, as well as large (4 $\mathrm{mm}$ in length) distal electrodes. Radiofrequency energy was applied between the distal electrode of the ablation catheter and a large surface area adhesive skin electrode (Valleylab, Boulder, Colorado) placed over the left scapula. Techniques for positioning the $a b$ lation catheter were described previously. ${ }^{1,3,6}$ For interruption of atrioventricular conduction, the catheter was advanced across the tricuspid annulus and manipulated to record the largest His electrogram. Ablation of right free wall and septal accessory pathways was performed by introducing the catheter in the femoral vein and positioning it at a site on the tricuspid annulus with a short local atrioventricular or ventriculoatrial activation time, or both. A retrograde aortic approach was used for left free wall accessory pathways. The catheter was positioned on the ventricular side of the mitral annulus at the site of earliest activation.

The location of the ablation catheter, energy delivery parameters (including voltage, current, power, duration and impedance) and electrophysiologic effects of every radiofrequency application were recorded in all 27 subjects. To determine if impedance was influenced by the size of the patient, body surface area was calculated for each patient using the formula of Dubois. ${ }^{7}$ To define the relation between lung volumes and impedance, forced vital capacity was measured within 24 hours of catheter ablation in 18 subjects using a precision handheld spirometer (Boehringer Laboratories, Germany).

The relation between clinical and ablation parameters, and impedance was analyzed using multivariate regression. $A$ value $<0.05$ was considered statistically significant.

In all, 257 applications of radiofrequency energy were delivered during the course of catheter ablation in the 27 patients. Mean impedance was $100 \pm 10 \mathrm{ohms}$ (range 77 to 132). There was a significant, direct correlation between body surface area and impedance $\left(r^{2}=\right.$ $0.44, p=0.0001$; Figure 1). Forced vital capacity was also independently predictive of impedance $\left(r^{2}=0.39, p\right.$ $=0.03$ ).

Neither age nor gender correlated with impedance. Impedance during applications that produced conduction block was slightly but significantly less than during ineffective applications $(98 \pm 9$ vs $101 \pm 10 \mathrm{ohms}$; $p=0.01$ ). Applied power did not appear to affect im- 
pedance, nor was there a difference in impedance between applications in the right heart and those in the left, nor between the 2 types of ablation catheter used.

Impedance during radiofrequency catheter ablation in humans is variable, with a range of $55 \mathrm{ohms}$ noted in this study. Impedance was directly proportional to body surface area and forced vital capacity. Impedance was significantly less during radiofrequency applications that were successful compared with during ineffective applications. No other clinical or energy delivery parameters appeared to affect impedance, nor did the 2 types of ablation catheters used in this study differ significantly.

The volume of a resistive medium interposed between 2 electrodes is proportional to the impedance to alternating current flow. The larger the body surface area, the greater the amount of tissue between the ablating and indifferent skin electrodes. The relation between body size and transthoracic impedance during defibrillation ${ }^{8}$ is consistent with this hypothesis.

A study of radiofrequency ablation in the left ventricle in experimental animals showed significantly higher impedances when a conventional distal electrode $(2 \mathrm{~mm}$ in length, $12.6 \mathrm{~mm}^{2}$ in surface area) was used compared with a large distal one $\left(3 \mathrm{~mm}\right.$ in length, $18.9 \mathrm{~mm}^{2}$ in surface area). ${ }^{9}$ The similar mean impedance values seen with the 2 different types of ablation catheter in the current study probably reflect the fact that distal electrode surface areas were the same.

Impedance during successful radiofrequency energy applications was slightly but significantly lower than during unsuccessful applications. Studies in animals, and a recent clinical report from our laboratory show that tissue heating causes impedance to decrease. ${ }^{10}$ This temperature dependence may also explain why effective applications were associated with a lower mean impedance, because some ineffective applications may have been the result of inadequate heating.

It is well known that phasic changes in lung volume with respiration produce corresponding fluctuations in transthoracic impedance. This phenomenon has been used to estimate minute ventilation in activity pacemakers, and for apnea monitoring with cutaneous electrodes. ${ }^{1-13}$ The influence of vital capacity seen in this study suggests that the volume of lung parenchyma between the endocardial and indifferent electrodes also sig- nificantly affects impedance to current flow during radiofrequency catheter ablation.

The results of this study suggest that the size of the patient can significantly affect impedance during radiofrequency ablation, which may in turn impact on the adequacy of lesion formation. For example, $60 \mathrm{~V}$ applied to a small patient in whom the impedance is $90 \mathrm{ohms}$ would result in delivery of $40 \mathrm{~W}$. In contrast, $60 \mathrm{~V}$ applied in a larger patient in whom the impedance is $120 \mathrm{ohms}$ would result in delivery of only $30 \mathrm{~W}$. Therefore, if a constant voltage radiofrequency generator is used for catheter ablation, the output voltage may need adjustment commensurate with the impedance of the patient.

1. Calkins H, Sousa J, El-Atassi R, Rosenheck S, de Buitleir M, Kou WH, Kadish AH, Langberg JJ, Morady F. Diagnosis and cure of the Wolff-Parkinson-White syndrome or paroxysmal supraventricular tachycardias during a single electrophysiologic test. $N$ Engl $J$ Med 1991;324:1612-1618.

2. Jackman WM, Wang X, Friday KJ, Roman CA, Moulton KP, Beckman KJ, McClelland JH, Twidale N, Hazlitt HA, Prior MI, Margolis PD, Calame JD, Overholt ED, Lazzara R. Catheter ablation of accessory atrioventricular pathways (Wolff-Parkinson-White syndrome) by radiofrequency current. $N$ Engl $J$ Med 1991;324:1605-1611.

3. Lee MA, Morady F, Kadish A, Schamp DJ, Chin MC, Scheinman MM, Griffin JC, Lesh MD, Pederson D, Goldberger J, Calkins $\mathrm{H}$, de Buitleir M, Kou WH, Rosenheck S, Sousa J, Langberg JJ. Catheter modification of the atrioventricular junction with radiofrequency energy for control of atrioventricular nodal reentry tachycardia. Circulation 1991;83:827-835.

4. Organ LW. Electrophysiologic principles of radiofrequency lesion making. Appl Neurophysiol 1976/77;39:69-76.

5. Wittkampf FHM, Hauer RNW, Robles de Medina EO: Control of radiofrequency lesions by power regulation. Circulation 1989;80:962-968.

6. Langberg JJ, Chin MC, Rosenqvist M, Cockrell J, Dullet N, Van Hare G, Griffin JC, Scheinman MM: Catheter ablation of the atrioventricular junction with radiofrequency energy. Circulation 1989;80:1525-1527.

7. Dubois EF. Basal Metabolism in Health and Disease. Philadelphia: Lea \& Febinger, 1936.

8. Sirna SJ, Ferguson DW, Charbonnier F, Kerber RE. Factors affecting transthoracic impedance during electrical cardioversion. Am J Cardiol 1988;62: 10481052.

9. Langberg JJ, Lee MA, Chin MC, Rosenqvist M. Radiofrequency catheter ablation: the effect of electrode size on lesion volume in vivo. $P A C E$ 1990;13: 1242-1248.

10. Harvey M, Kim YN, Sousa J, El-Atassi R, Morady F, Calkins H, Langberg JJ. Impedance monitoring during radiofrequency catheter ablation in humans. PACE 1992;15:22-27.

11. Lau CP, Antoniou A, Ward D, Camm AJ. Initial clinical experience with a minute ventilation sensing rate modulated pacemaker: improvements in exercise capacity and symptomatology. PACE 1988;18:1815-1822.

12. Brouillette RT, Morrow $\Lambda J$, Weese-Mayer DE, Hunt CE. Comparison of respiratory inductive plethysmography and thoracic impedance for apnea monitoring. J Pediatr 1987;111:377-383.

13. Grenvik A. Ballou S, McGinley E. Miller JE. Cooky WL. Safar P: Impedance pneumography. Comparison between chest impedance changes and respiratory volumes in 11 healthy volunteers. Chest 1972;62:439-443. 